\title{
Parcelas de agrado alrededor de Santiago y Valparaíso. ¿Migración por amenidad a la chilena? ${ }^{1}$
}

\author{
Rodrigo Hidalgo ${ }^{2}$, Axel Borsdorf ${ }^{3}$ y Felipe Plaza ${ }^{2}$
}

\begin{abstract}
RESUMEN
El artículo analiza el marco legal, distribución y estructura espacial de las migraciones por amenidad en las regiones montañosas chilenas (cordillera de la Costa, cordillera de los Andes) y sus tendencias en las últimas décadas. Se presentan tres casos de estudio, dos en regiones montañosas y un caso en un área de semimontaña. Basado en datos cuantitativos, mediante el análisis de datos censales 1992-2002, y cualitativos (entrevista a expertos), contempla también las relaciones entre vecinos y los conflictos entre los inmigrantes y la población tradicional. El artículo finaliza con una evaluación de las consecuencias económicas y sociales de los nuevos parques residenciales o las Ilamadas parcelas de agrado constituidas por lotes de más de $5.000 \mathrm{~m}^{2}$.
\end{abstract}

Palabras clave: Amenidades, parcelas de agrado, periferias metropolitanas, diferenciación residencial.

\begin{abstract}
The article analyzes the legal framework, distribution and spatial structure of amenity migration in mountain regions in Chile (Cordillera de la Costa, Cordillera de los Andes) and their trends in recent decades. Presents three case studies, two in mountainous regions and one in a semi-mountainous area. Based on qualitative data (interview with experts), and the relations between neighbors and the conflicts between immigrants and the traditional population. The article ends with an evaluation of the economic and social consequences of new parks or residential plots pleased calls up a batch of over 5,000 $\mathrm{m}^{2}$.
\end{abstract}

Key words: Amenities, pleasure lots, metropolitan peripheries, residential differentiation.

Las migraciones son un fenómeno geográfico que refleja la distribución de la población en el espacio. Por lo general, responden a ciertos intereses tales como económicos, culturales y sociales, que dependen de fuerzas de atracción y repulsión, lo que las caracteriza en cuanto a su origen-

1 Proyectos FONDECYT No 1030472 , N 01060759 y de Cooperación Internacional № 7080114. Artículo recibido el 3 de marzo de 2009 y aceptado el 24 de marzo de 2009. destino, temporalidad y al grupo humano implicado. Durante las últimas décadas se están haciendo frecuentes a escala interna, desde las grandes áreas urbanas hacia sus zonas periféricas. La respuesta a esto puede ser explicada por las amenidades. Moss

\footnotetext{
2 Instituto de Geografía, Pontificia Universidad Católica de Chile (Chile).

E-mail: hidalgo@geo.puc.cl; fplaza@geo.puc.cl

3 Instituto de Geografía, Universidad de Innsbruck (Austria).E-mail: axel.borsdorf@uibk.ac.at
} 
(2006) define las migraciones por amenidad como el traslado permanente o temporal de personas a ciertos lugares, debido a la percepción de mejora en la calidad ambiental y diferenciación cultural del lugar de destino. Este fenómeno ha sido analizado recientemente en varias regiones montañosas del mundo, como Estados Unidos, Canadá, Costa Rica, Argentina, los Alpes europeos, Noruega, Suecia, Filipinas, Australia y Nueva Zelanda (ver las contribuciones de Moss, 2006). Los casos de estudio en Costa Rica (Chaverri, 2006) y Argentina (Otero et al., 2006) muestran que las migraciones por amenidad han Ilegado a América Latina. El caso argentino se caracteriza por largos desplazamientos de hasta $2.000 \mathrm{~km}$, mientras que los costarricenses muestran una clara tendencia a la migración por amenidad hacia comunidades periurbanas en las montañas cercanas a la capital (San José: 1 millón de habitantes), a unos $10 \mathrm{~km}$.

Stewart (2002) analiza también las migraciones por amenidad más bien desde una perspectiva teórica y social, aludiendo principalmente a que ellas corresponden a un desplazamiento de población desde las áreas urbanas hacia las "áreas rurales de ocio", es decir, aquellos lugares más ricos paisajísticamente con alto valor recreativo, no necesariamente de alta montaña, que generan como consecuencia un aumento de población en estas áreas rurales, proceso al que denomina "contraurbanización". Yian y Muller (2007) señalan que las áreas de destino donde se produce migración por amenidad son lugares atractivos y cómodos, con bajos niveles de contaminación y de ruido, lo que puede englobarse en superficies con una alta diversidad de elementos naturales. Similar es la visión de Kuentzel y Mukudan (2005), ya que para ellos la migración por amenidad ayuda a potenciar el turismo y por extensión el desarrollo de las comunidades rurales, lo que se evidencia como una forma particular de ordenamiento del espacio rural, es decir, el turismo por amenidad es un paso previo a las localidades emplazadas en lugares que presentan amenidades, cuestión que en algunas dimensiones es apreciable en San José de Maipo, Olmué y Curacaví.

La traducción al alemán del término "migración por amenidad" hecha por Perlik
(2006), quien lo Ilama wohlstandswanderung (migración afluente), deja en claro que la experiencia de la migración por amenidad está fuertemente conectada con las clases medias y altas, por lo tanto depende de un cierto nivel o estándar de vida. Pues como señala Stewart (2002), una importante parte de los migrantes renuncian a mejores salarios, mientras se acomodan al nuevo lugar de residencia, sin tener la necesidad imperiosa de tener que trabajar o encontrar un empleo rápidamente. Bajo este aspecto es muy interesante estudiar el caso chileno. Chile abandonó la antigua doctrina económica de la Sustitución de Importaciones (ISI) en el año 1973 y la reemplazó un sistema que buscaba el crecimiento económico basado en la desregulación de la economía y la apertura al comercio exterior. En este sentido, las medidas más características fueron la reducción sustancial de las protecciones arancelarias y el incentivo a la participación de capitales extranjeros en las actividades económicas del país, acciones que no llevan a afirmar que la globalización se ha estado llevando a cabo durante 35 años. Existen muchas desventajas en este tipo de desarroIlo que no pueden ser discutidos en este artículo, pero sin lugar a duda el nivel o estándar de vida ha aumentado considerablemente. La extrema pobreza ha sido erradicada casi por completo y los indicadores económicos en Chile, comparados con los países latinoamericanos, muestran su posición de liderazgo en el subcontinente. A pesar del gran proceso económico, la diferencia entre las clases altas y bajas ha aumentado considerablemente y la búsqueda de seguridad ha concluido en nuevas formas de segregación socioespacial (como las comunidades enrejadas o ciudades enrejadas, ver Borsdorf e Hidalgo, 2008a).

En este contexto, el aumento de las migraciones por amenidad en las últimas dos décadas puede ser interpretado como una continuación lógica de este desarrollo y como una nueva dimensión de segregación social. Durante el periodo de Sustitución de Importaciones, en las ciudades se produjo una diferenciación residencial importante, pues aparecieron los barrios marginales, mientras que, por otra parte, los ricos se alejaban del centro de la ciudad, forjándose lo que se conoce como la "ciu- 
dad rica" y la "ciudad pobre", como consecuencia de la inequidad social y económica que se evidenció con la aplicación de dicho modelo económico. Con la emergente globalización de este patrón, cambió hacia uno fragmentado que pudiese describirse como "microsegregación" (Sabatini, 1998). Janoschka, (2002) mirando el ejemplo de Buenos Aires, lo llamó patrón "archipiélago", constituido por islas de ricos en un océano de pobres (ver también Janoschka \& Borsdorf, 2005). Sin embargo, el hecho que cada vez más seguido los ricos quieran sus nuevas residencias fuera del círculo urbano y compren lotes de las antiguas tierras agrícolas en el campo o "parcelas de agrado" de $5.000 \mathrm{~m}^{2}$ o más, no puede ser explicado con la microsegregación. Lo anterior es una nueva forma de macrosegregación que no se da en el contexto interurbano, sino que en el contexto de las relaciones urbano-rurales (Borsdorf, Hidalgo \& Sánchez, 2007).

Este fenómeno no ha sido analizado aún en Chile. Sin embargo, algunos autores han trabajado el fenómeno de postsuburbanización (Escolano \& Ortiz, 2007; Hidalgo, 2005). Un nuevo estudio ha mostrado que a pesar que estas tendencias puedan surgir en el futuro, hasta el momento el desarrollo en Chile sigue caracterizado por procesos periurbanos (Borsdorf \& Hidalgo, 2008b). Es así como las preguntas de esta investigación se configuran: ¿cuáles son las características de la migración por amenidad en las áreas metropolitanas chilenas de Santiago y Valparaíso?, ¿cuándo empezó este proceso?, ¿cuál es su intensidad?, ¿cuáles son las fuerzas motrices?, ¿la migración por amenidad chilena puede ser vista como una contribución a un desarrollo regional sustentable?

\section{Marco metodológico y casos de estudio}

El presente artículo se basó en un análisis cuantitativo y cualitativo del fenómeno migratorio. Las fuentes de información al respecto provienen de diversa índole. En primer lugar, se llevó a cabo una revisión bibliográfica y de antecedentes en torno al tema que, sin lugar a duda, otorgan un sustento teórico contingente importante. Tam- bién se trabajó con información censal de los últimos dos censos de población y vivienda acontecidos en Chile en los años 1992 y 2002. Dichos datos fueron procesados con el software Redatam $+S p$ Process de CELADE, con el objeto de obtener algunos indicadores como el crecimiento neto total, medio intercensal y tasa de migración de las comunas de estudio. Por otra parte, el artículo se sustenta en entrevistas a actores estratégicos relevantes de las tres comunas de estudio. Finalmente, el punto de vista perceptual de la población también fue considerado en encuestas y entrevistas aplicadas a los residentes.

La zona central de Chile está dominada por dos grandes aglomeraciones urbanas: el Área Metropolitana de Santiago con alrededor de 5,5 millones de habitantes y el Área Metropolitana de Valparaíso-Viña del Mar con alrededor de 1,2 millón de habitantes. Santiago está localizado en la depresión tectónica (valle longitudinal) entre la cordillera de los Andes (hasta $6.900 \mathrm{~m}$ ) y la cordillera de la Costa (hasta $2.400 \mathrm{~m}$ ). Valparaíso y Viña del Mar son ciudades costeras, localizadas sobre la plataforma marina y separadas del resto del país por la cordillera de la Costa (Figura $\mathrm{N}^{\circ} 1$ ).

Los tres casos de estudio que serán analizados en este artículo son el Cajón del Maipo y su ciudad central San José de Maipo (13.400 habitantes en el 2002), que se encuentra a $40 \mathrm{~km}$ o $50 \mathrm{~km}$ de la ciudad de Santiago y a una altitud de $960 \mathrm{~m}$ en la alta cordillera. Por otro lado, Olmué (14.100 habitantes en el 2002) es una ciudad sobre la ladera oeste de la cordillera de la Costa, localizada a unos $80 \mathrm{~km}$ del centro de Santiago y $50 \mathrm{~km}$ del centro de Valparaíso, a una altitud de $300 \mathrm{~m}$. Finalmente, Curacaví (24.298 habitantes en el 2002) es una ciudad que se encuentra a $40 \mathrm{~km}$ de Santiago, inmersa en un valle a 205 m.s.n.m. rodeado por cerros de la cordillera de la Costa.

Las tres áreas de estudio están caracterizadas por actividades turísticas. Cerca de Olmué se encuentra el Parque Nacional y Reserva de la Biosfera La Campana. En tanto, dentro de los hitos del Cajón del Maipo se encuentran el monumento natural El Morado y baños termales (baños Morales y ba- 
ños Colina). Mientras que Curacaví posee una Zona de Preservación del Medio Natural localizada en la semimontaña de la comuna, y a $40 \mathrm{~km}$ de esta se localiza la Reserva Nacional Lago Peñuelas. Los paisajes en los tres lugares son espectaculares: en el Cajón del Maipo existe una vista del volcán San José (5.856 m), las puntas del Retumbadero $(4.850 \mathrm{~m})$ y del Diablo $(4.210 \mathrm{~m})$. Las aguas del río Maipo y la diversidad de la vegetación en sus laderas poseen una gran riqueza escénica y paisajística. El área también ofrece un excelente lugar para esquiar en Lagunillas.

La región de Olmué dispone de vistas espectaculares de la punta del cerro La Campana $(1.828 \mathrm{~m})$, El Roble $(2.222 \mathrm{~m}$ ) y a cumbres adyacentes. El área tiene temporadas favoritas: en primavera miles de flores transforman el área en un jardín, en verano el bosque natural provee sombra y en otoño existe un espectáculo de hojas de variados colores.

En Curacaví, las vistas panorámicas que se aprecian al descender de la cuesta Lo Prado permiten apreciar el valle en total magnitud, sus suaves lomajes y el color verde de sus cerros. El aire de Curacaví es también un factor relevante, pues estando tan cerca de una de las ciudades más contaminadas del país ${ }^{4}$ (Santiago), su aire presenta condiciones de pureza y limpieza envidiables por otras ciudades aledañas y que contribuyen de sobremanera a la vista de esta ciudad. Además, el paisaje adquiere un colorido anaranjado, ya que a lo largo de este se presenta la flor "palo negro" (Balbisia pendicularis) en forma de matorral arbustivo durante todo el año.

Las características presenciadas en los tres casos de estudio han favorecido también el turismo por amenidad. La infraestructura turística en los tres lugares es muy completa; los servicios incluyen desde hoteles de lujo hasta los más económicos, cabañas y moteles, piscinas públicas y áreas de picnic, camping, rodeo, arriendo de bicicletas y caballos, cabañas en la montaña y tours guiados, y en el Cajón del Maipo, incluso hay actividades de rafting. Los tres lugares llevan a cabo festivales de cultura que han sido preservados por las localida-

\footnotetext{
4 Según la Comisión Nacional del Medio Ambiente (CONAMA), Santiago es considerada una "zona latente", es decir, una ciudad donde la medición de los contaminantes en el aire se sitúa entre el $80 \%$ y $100 \%$ de la norma ambiental vigente.
}

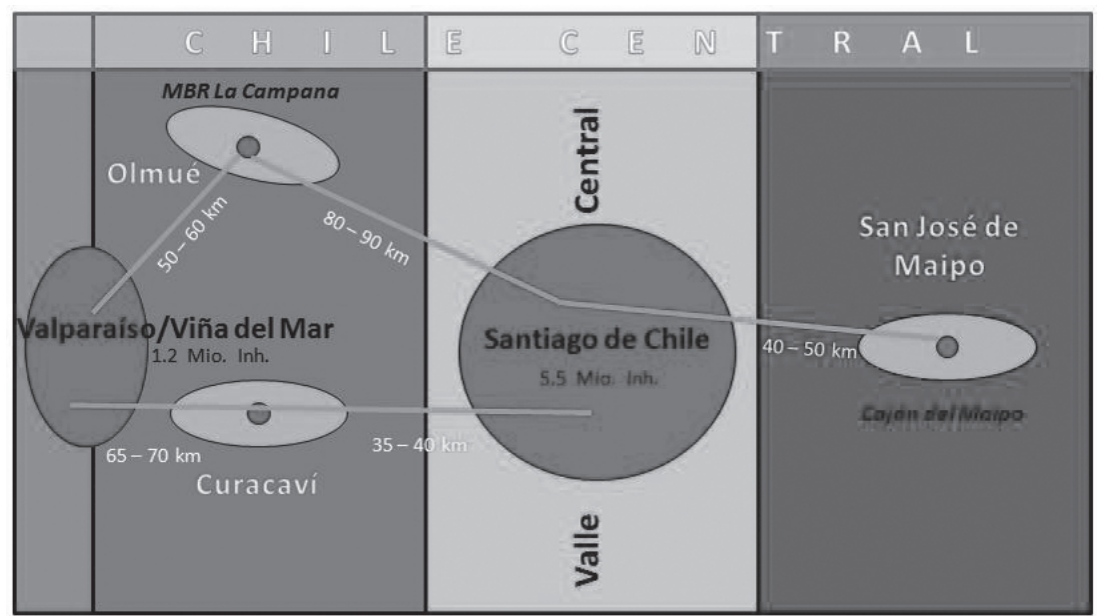

Fuente: Elaboración propia. 
des rurales hasta nuestros días. Estos sectores también ofrecen un agradable microclima con bajas temperaturas, refrescantes vientos y bajos niveles de contaminación. Pueden ser considerados como sommerfrische (concepto alemán que se refiere al retiro hacia lugares rurales durante el verano) para la población metropolitana que sufre por las altas temperaturas estivales, por la niebla y el smog durante el otoño e invierno. Es así como un grupo de alemanes y sus descendientes instalaron una casa de vacaciones (deutsches ferienhein) en Limache, cerca de Olmué, y dos cabañas en la montaña (Lagunillas y Lo Valdés), en el Cajón del Maipo, comenzando así la tradición europea del sommerfrische en Chile a comienzos del siglo XX. Esto incluso contribuyó a que estas regiones sean consideradas como destinos turísticos para Europa. Además, las visitas a Chile de Charles Darwin en 1834 y sus descripciones hicieron que ambas regiones (Cajón del Maipo y Olmué) fueran muy conocidas para el mundo angloparlante (Elórtegui \& Moreira, 2007). Curacaví, por su parte, representa un espacio que está en la historia del mundo rural chileno, donde las disputas entre españoles e indígenas por las fértiles tierras cercanas al Puangue lo pusieron en valor desde la época colonial (véase el clásico estudio de Borde y Góngora, 1956). En definitiva, los orígenes de la migración por amenidad en los tres lugares es una consecuencia del turismo por amenidad. Ello porque el equipamiento turístico genera incentivos a la migración por amenidad temporal, una de las modalidades para este tipo de migración que define Moss (2006).

Al contrario de las poblaciones andinas, los chilenos no están acostumbrados a vivir en elevadas altitudes, y así aprovechar la altura de Olmué y Cajón del Maipo, como también la de los lomajes en Curacaví. Sin embargo, en las últimas décadas el andinismo, el hiking, el mountan biking, el rafting y el montañismo se han convertido en deportes populares al mismo tiempo en Chile.

\section{El marco legal}

Uno de los hitos que marca el proceso de ocupación de los espacios rurales circun- dantes a las ciudades y áreas metropolitanas chilenas tiene relación con la promulgación del Decreto con Fuerza de Ley (DFL) 3.516 de 1980, comúnmente conocido como la "ley de las parcelas de agrado" (MINAGRI, 1980).

Haciendo una revisión de la historia reciente de la legislación atingente a la parcelación del suelo rural, es posible apuntar que antes de la promulgación del DFL 3.516 las normas existentes sobre subdivisión de predios rústicos estaban contenidas en el Decreto Ley N $N^{\circ} 752$ de 1974 del Ministerio de Agricultura, que fue modificado en 1978 a través del DFL 1-2.345, del mismo Ministerio, dada la gran necesidad de adecuar también esta legislación a la política general del gobierno, que tendía a dar una mayor libertad al mercado (Boletín 2.691-01). Las normas vigentes hasta ese momento tenían por finalidad la preservación de las tierras y pretendieron evitar tanto el surgimiento de minifundios como la disminución de predios rústicos. La superficie mínima exigida a los predios para poder ser subdivididos era de 8 hectáreas de suelo de riego clase I y II, de lo contrario, el Servicio Agrícola y Ganadero (SAG) era la entidad encargada de dar autorización a la subdivisión, conforme las disposiciones del citado Decreto Ley $N^{\circ} 752$ (Maturana, 2002).

Bajo este contexto, en el año 1980 es promulgado el DFL 3.516 que establece las nuevas normas sobre división de predios rústicos. Publicado en el Diario Oficial $N^{\circ} 30.829$, de acuerdo al mensaje presidencial, el decreto tiene por objeto "establecer la libertad para dividir los predios rústicos de aptitud agrícola, ganadera o forestal, manteniéndose el destino primitivo, respecto de los lotes resultantes y sujetándose a las normas establecidas en la Ley General de Urbanismo y Construcciones" (Boletín 2.691-01). Sin embargo, esta libertad de subdivisión de predios se supeditaba a dos restricciones. En primer lugar, los predios resultantes de la subdivisión deben tener una superficie no inferior a $5.000 \mathrm{~m}^{2}$, es decir, 0,5 hectáreas; en segundo lugar, los predios resultantes de estas subdivisiones están impedidos de cambiar su destino. Junto con ello, notarios y conservadores de bienes raí- 
ces tienen la obligación de no autorizar escrituras públicas, ni inscribirlas, respectivamente, si no se ajustan a las limitaciones establecidas (CONAMA, 1999).

Desde la promulgación del citado decreto se comienza llevar a cabo un intenso proceso de subdivisión del suelo rural en gran parte del territorio nacional. Para el caso de la Región Metropolitana de Santiago, entre 1994 y el 2002 se acogieron a la citada ley cerca de 380.000 ha. Las parcelas de agrado cobran un importante valor como motor de cambio de dichos territorios, y ellas adoptan diversas tipologías, desde la edificación individual hasta conjuntos de lotes que se agrupan en la modalidad de condominio, que en términos legales son agrupaciones de parceleros. Existe en estos conjuntos de viviendas accesos controlados y en algunas ocasiones sistemas de vigilancia permanente, que son organizados por los propios vecinos que habitan en ellos (Hidalgo et al., 2005).

El censo de 2002 incluye a las parcelas de agrado como una forma específica de asentamiento y las define como: "asentamiento humano, concentrado o disperso que se ubica en una o más propiedades de pequeña extensión, inferior a media hectárea (5.000 metros cuadrados), con nombre propio común a todas ellas. La parcela de agrado, por su dimensión no constituye una explotación agrícola, aun cuando existan cultivos al interior de ella; se diferencia de la parcela agrícola por el tipo de edificación moderna de la vivienda, correspondiente a un nivel socioeconómico medio alto y alto. Por lo general, la parcela de agrado se ubica en las cercanías de los centros urbanos de importancia; ellos forman un conjunto de varias propiedades que se reconocen con un nombre propio común, que generalmente se deriva del nombre del predio que las originó, independientemente del nombre propio que pudiere tener cada propiedad. La parcela de agrado pierde su categoría si su monto poblacional corresponde a la de "Aldea" (entre 301 y 1.000 habitantes)" (INE, 2002). Según el citado censo, en el año 2002 se registraron 337 parcelas de agrado en la Región Metropolitana, región donde se localizan San José de Maipo y
Curacaví, contemplando una población regional en parcelas de agrado de 31.304 habitantes, mientras que en la Región de Valparaíso, donde se localiza Olmué, residen 838 habitantes en el mismo tipo de asentamiento.

Tanto los efectos descritos provocados por la aplicación del DFL 3.516 como el alto potencial vigente en la construcción de viviendas en parcelas de agrado en las diferentes comunas de la periferia del AMS, son unos de los mayores desafíos a los que está enfrentado el sistema de planificación territorial vigente en el país. Aunque la ampliación del área administrativa de los Planes Reguladores Intercomunales y Metropolitanos ha logrado al menos detener la inscripción de nuevas subdivisiones de $5.000 \mathrm{~m}^{2}$, igualmente ellos no son retroactivos, quedando en el mercado de la tierra una alta disponibilidad de suelo acogido a la "ley de las parcelas de agrado". En este sentido, en la actualidad las autoridades se encuentran estudiando una modificación de la Ley General de Urbanismo y Construcciones en la que se pretenden incluir nuevas figuras de planificación amparadas en el Desarrollo Urbano Condicionado, formulado para velar supuestamente por un crecimiento armónico de los asentamientos humanos en las periferias de las ciudades y que permitan sentar las bases para regular los requerimientos mínimos de los equipamientos e infraestructuras que mitiguen las externalidades negativas que dichas ocupaciones provocan en los espacios donde se instalan, como lo que acontece en Chicureo, en la provincia de Chacabuco.

\section{Migración por amenidad hacia las montañas. ¿Un nuevo fenómeno en Chile?}

El absentismo ha sido común en Chile desde principios de la colonia. Los dueños de las tierras estaban obligados a vivir en la ciudad durante la mayor parte del año y trataban de visitar sus tierras cuantas veces fuese posible y pasar ahí los fines de semanas y las vacaciones. Se sabe por muchos reportajes contemporáneos que el fundo era visto como Arcadia: valía la pena vivir en la sucia y ruidosa ciudad cuanto fuera posible 
y pasar algunos días al aire fresco y hermoso paisaje del medio ambiente rural (Wilhelmy \& Borsdorf, 1984). Habrá segunda residencia en la migración por amenidad cuando el individuo adquiera en el lugar ciertas comodidades que contribuyan a mejorar su calidad de vida.

En el siglo XIX muchas familias ricas instalaron sus segundas viviendas en el campo; mismo proceso que se evidencia en el valle del Puangue, en la actual comuna de Curacaví, tras el fin del fundo con la aparición de las hijuelas y parcelas (Borde y Góngora, 1956). Esta idea es completamente europea y fue introducida por los colonos europeos (italianos, franceses, suizos y alemanes) que Ilegaron a Chile a mitad del siglo. Los primeros prefirieron la playa, pero cuando los extranjeros y las segundas generaciones de colonos alemanes empezaron a escalar los Andes, las montañas fueron convirtiéndose cada vez en más atractivas como localización de segunda residencia. El turismo de montaña también fue introducido por clubes alemanes (deutscher Ausflugsverein, deutscher Andenverein), que construyeron una red de carpas de montañas en las altitudes. En este sentido ya se evidencia, según Stewart (2002), la relación existente entre la migración por amenidad, turismo y segunda residencia; además, enfatiza en que la segunda residencia es el paso intermedio entre el turismo y la migración. Por otra parte, otros autores creen que habrá segunda residencia cuando el individuo atraído por las amenidades adquiera las mejores condiciones biofísicas del lugar (Yin y Muller, 2007).

A pesar que estas fases, en un sentido estricto, no pueden ser consideradas como migración por amenidad, la creación de hogares de veraneo por parte de los habitantes metropolitanos, empezando con la construcción de la línea de ferrocarril hacia la montaña (en 1906 la línea de ferrocarril del Maipo fue construida por una corporación alemana; el ferrocarril Santiago-Valparaíso se inaugura en 1863, pasando por Limache, a solo $10 \mathrm{~km}$ de Olmué), ya comparte muchas de sus características. El surgimiento del turismo intensificó la moda aún más, pero solo a partir de los años 80 es que la migración hacia la montaña presentó las características de migración por amenidad, incluyendo los desplazamientos diarios de larga distancia, residencias para adultos mayores, y, lo más importante, la búsqueda de servicios y facilidades naturales y culturales.

\section{Fases de la migración por amenidad en los casos estudiados}

Las fases o etapas detalladas anteriormente pueden ser observadas en Olmué, donde durante la colonia una encomienda (un cuasi latifundismo feudal) fue instaurada. En el siglo XIX fueron construidas las casas de veraneo para las altas clases sociales; el turismo, por otro lado, empezó después de la Segunda Guerra Mundial. A partir de 1980, con el crecimiento económico, los adultos mayores migraron hasta ahí, y luego de la consolidación del camino de cuesta La Dormida, que acortó el tiempo de viaje a Santiago en 1,5 hora, los migrantes diarios de larga distancia, también denominados viajeros, empezaron a trasladarse a Olmué (Figura $N^{\circ} 2$ ). El Cajón del Maipo, en tanto, no tuvo una encomienda, sino que la colonización del valle solo empezó en las últimas décadas del siglo XVIII. Sin embargo, un increíble desarrollo de segundos hogares para la población metropolitana empezó medio siglo después.

En Curacaví, la situación es similar a Olmué, pues también existió encomienda de los primeros indios que habitaban las orillas del Puangue, principal curso de agua superficial de la comuna, en el siglo XVI. Durante todo el siglo solo vivían unos cuantos habitantes, que se fueron incrementando con los viajes realizados entre Santiago y Valparaíso. A diferencia de Olmué y del Cajón del Maipo, la puesta en marcha del ferrocarril Santiago-Valparaíso postergó el desarrollo de Curacaví, que solo retomó con la masificación del automóvil y con la pavimentación de la carretera que une Santiago y Valparaíso-Viña del Mar, retornando a Curacaví la función de tambo o centro de acopio que tuvo desde la época prehispánica y colonial. 
En consecuencia, el mejoramiento del sistema de transporte metropolitano y el crecimiento económico han significado que desde 1975 la migración por amenidad haya surgido a pasos agigantados. Los tres casos de estudio pueden ser comparados en un primer paso como se muestra en el Cuadro $N^{\circ} 1$.

Figura $\mathrm{N}^{\circ} 2$

Fases de la migración por amenidad en Olmué

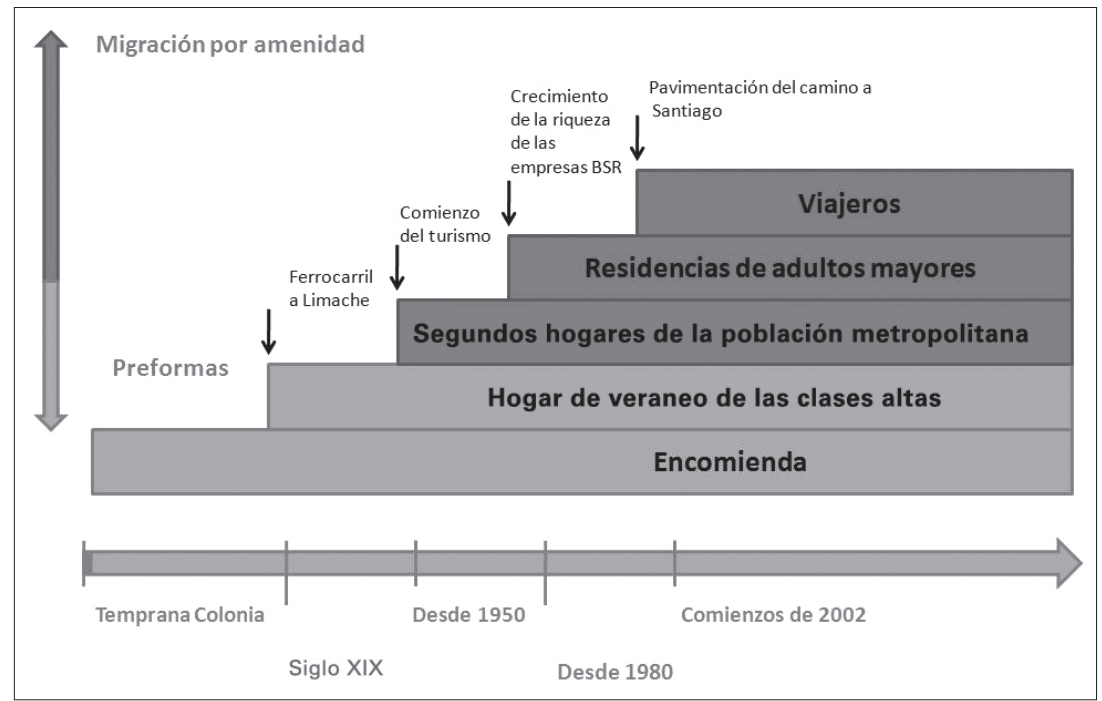

Fuente: Elaboración propia.

Cuadro $\mathrm{N}^{\circ} 1$

Características de la migración por amenidad en los casos de estudio

\begin{tabular}{|c|c|c|}
\hline Cajón del Maipo & Olmué & Curacaví \\
\hline Paisaje de alta montaña & $\begin{array}{l}\text { Paisaje de montañas medi- } \\
\text { terráneas }\end{array}$ & $\begin{array}{l}\text { Paisaje de lomajes suaves } \\
\text { rodeado por cerros de la } \\
\text { cordillera de la Costa }\end{array}$ \\
\hline $\begin{array}{l}\text { La migración por amenidad } \\
\text { empezó antes de } 1975\end{array}$ & $\begin{array}{l}\text { La migración por amenidad } \\
\text { es bastante nueva ( } 2002)\end{array}$ & $\begin{array}{l}\text { La migración por amenidad } \\
\text { comenzó a partir de } 1992\end{array}$ \\
\hline $\begin{array}{l}\text { Servicios y facilitadores na- } \\
\text { turales y culturales }\end{array}$ & $\begin{array}{l}\text { Amenidades climáticas y de } \\
\text { paisaje }\end{array}$ & $\begin{array}{l}\text { Amenidades climáticas y de } \\
\text { paisaje, también facilitadores }\end{array}$ \\
\hline $\begin{array}{l}\text { La migración por amenidad } \\
\text { no es organizada }\end{array}$ & $\begin{array}{l}\text { La migración por amenidad } \\
\text { fue parcialmente organiza- } \\
\text { da en parte por empresas } \\
\text { inmobiliarias }\end{array}$ & $\begin{array}{l}\text { La migración por amenidad } \\
\text { fue facilitada por la norma- } \\
\text { tiva legal y concretada por } \\
\text { empresas inmobiliarias }\end{array}$ \\
\hline
\end{tabular}

Fuente: Elaboración propia. 


\section{Factores de atracción: servicios y facilitadores de las áreas de estudio}

\section{Olmué}

Olmué está localizado dentro de un paisaje montañoso mediterráneo. El cerro La Campana, que incentivó a Charles Darwin a subirlo, sobrepasa el valle hasta una altura relativa de $1.500 \mathrm{~m}$, dándole a la ciudad una característica comparable a ciertas partes del sur de los Alpes europeos o las montañas de Italia, Grecia o España. La vegetación es mediterránea y varía con la altitud. La endémica palmera chilena (Jubaea chilensis, Figura $\mathrm{N}^{\circ} 3$ ), incluso agrega un cierto toque tropical; también es endémico el roble de Santiago (Nothofagus macrocarpa). Las rocas graníticas de la cordillera muestran formas maravillosas del tipo acumulación de bolones y tors o castle kopje. El Parque Nacional y Reserva de la Biosfera La
Campana tiene una excelente infraestructura y ofrece tours guiados para distintos niveles de expertice (Elórtegui \& Moreira, 2007).

El clima es moderado-mediterráneo con alguna influencia de la montaña. Los veranos son secos y calurosos (hasta $30^{\circ} \mathrm{C}$ al mediodía), pero refresca en las noches (hasta $18^{\circ} \mathrm{C}$ ), haciendo que sean agradables; rara vez hay tormentas y la precipitación se concentra en invierno. Ocasionalmente existe escarcha en el valle, sin embargo, la calefacción es necesaria en el periodo invernal. No hay evidencias científicas, pero la región es bien conocida por su microclima, lo que alivia los efectos del reumatismo, artritis y problemas toráxicos, además de sus frutas, plantaciones de paltas e invernaderos, por lo que es referida como uno de los huertos de Chile.

La migración por amenidad se inició con el turismo, el que empezó en Olmué en el año 1956, cuando una familia alemana se

Figura $\mathrm{N}^{\circ} 3$

Paisaje en el Cajón del Maipo (Izquierda) y la región de Olmué (Derecha)

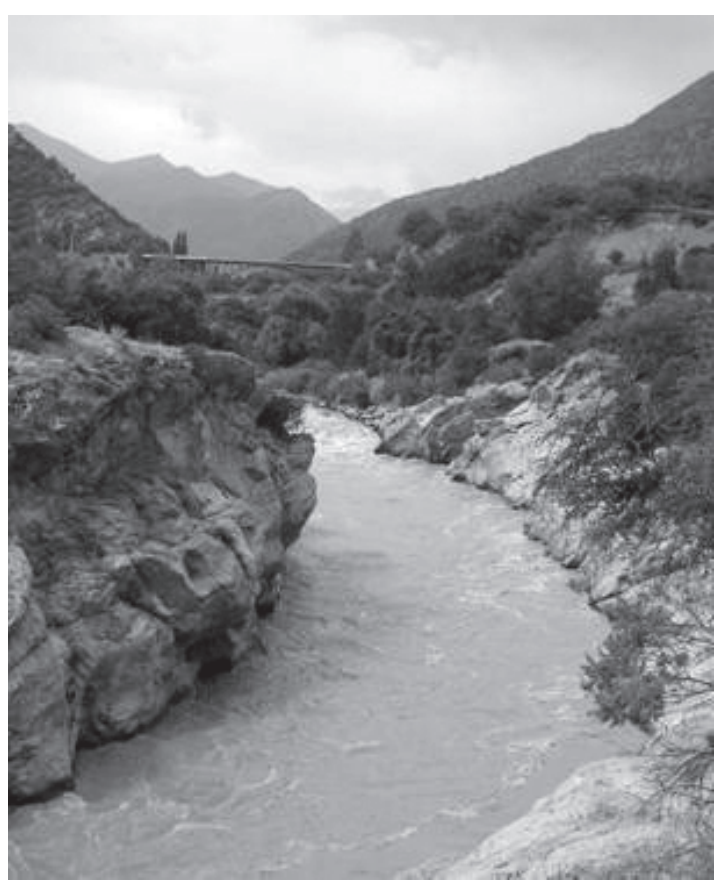

Fuente: Colección personal de los autores.

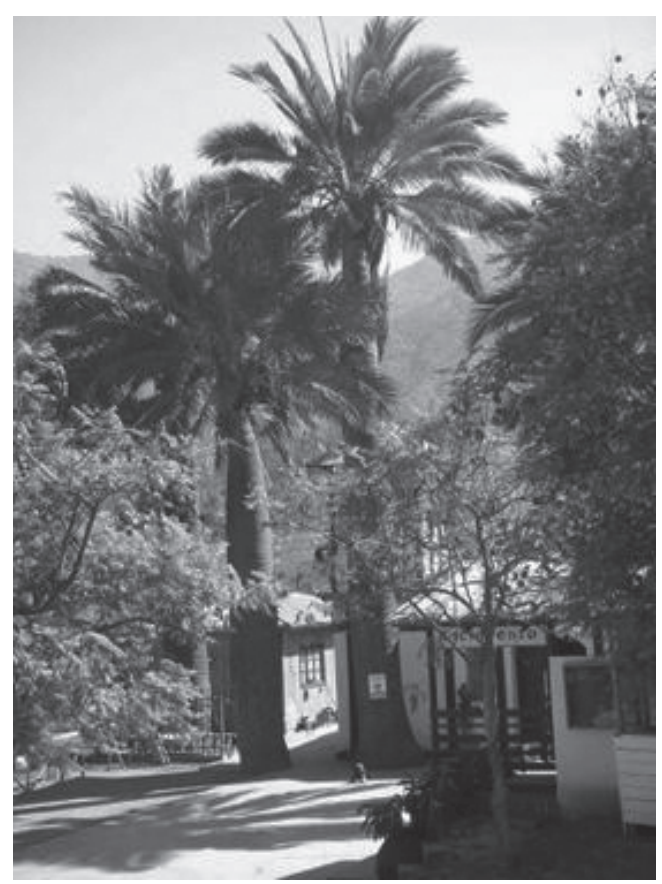


instaló ahí y pronto abrieron un pequeño hostal que hoy es un hotel de cinco estreIlas. La presente infraestructura turística incluye hoteles buenos y regulares, casi todos equipados con piscinas, con tratamientos de belleza y salud, moteles, cabañas, todo tipo de restaurantes (chilenos, alemanes y cocina europea), tiendas de souvenir, información turística, cabañas de montaña, un parque nacional bien equipado, cabalgatas, arriendo de bicicletas, piscina pública con áreas de picnic y otras áreas de picnic. Una vez al año el Festival del Huaso de Olmué, con actividad de rodeo y folclore, atrae a muchos visitantes. La historia se remonta al año 1612 cuando la encomendera Mariana de Osorio donó el territorio de Olmué a los indios picunches. Hay ciertos monumentos históricos, como iglesias coloniales y la iglesia de peregrinaje Niño de Dios, localizadas en un bello paisaje montañoso.

\section{Cajón del Maipo}

San José, la ciudad central del Cajón del Maipo, está localizada dentro de un paisaje de altas montañas. Fue fundada en 1792 en conjunto con las minas de plata cercanas. La iglesia, levantada en 1798 con un estilo clásico, el ex Sanatorio de Laennec y la estación de ferrocarril, que fue declarada Monumento Nacional, apuntan a la rica historia del lugar. Sin embargo, al contrario de Olmué, la migración por amenidad está menos concentrada en una sola ciudad, y más bien dispersa a lo largo de todo el Cajón del Maipo. Las aguas del río, la esplendorosa vista de las montañas y el clima templado, mucho más fresco que en Santiago y aún más frío por los vientos de montaña que garantizan mañanas y tardes frescas, las opciones para los montañistas en el verano y el esquí en el invierno son los más importantes servicios que ofrece la zona.

El turismo de igual forma ha sido parte de los orígenes de la migración por amenidad y data del siglo XIX, cuando el primer gran hotel fue abierto. Se intensificó con la primera construcción (militar) del ferrocarril en 1906, la cual era abierta al público durante los fines de semana. La infraestructura turística es aún mayor que la de Olmué. Diferentes categorías de hoteles, catorce con tres o cuatro estrellas, un gran hotel de cin- co estrellas, cabañas, siete sitios de camping, once restaurantes de alto nivel con comidas regionales y alemanas, algunas cabañas de montaña, oportunidades para practicar rafting y pescar, termas y piscinas, tours guiados en las 3.000 hectáreas del Monumento Natural El Morado hacia los glaciares, lago y aguas termales Parimavidas. Las termas están accesibles desde Villa del Valle, Valle de Colina y El Plomo. También existe otra reserva natural de 3.600 hectáreas, el Santuario de la Naturaleza Cascada de las Ánimas, que también ofrece hiking y espectaculares vistas. El valor simbólico del Cajón del Maipo (Figura $N^{\circ} 3$ ) puede ser apreciado a través del diario online Dedal de Oro, el cual incluye literatura e historia del valle ${ }^{5}$.

\section{Curacaví}

Curacaví se localiza en un valle de suaves lomajes formado por el descenso de los cordones montañosos siempre verdes de la cordillera de la Costa, en la zona central de Chile, donde prima la tranquilidad de su gente y su naturaleza. Se caracteriza por presentar un clima mediterráneo moderado, en que en los meses de invierno se presentan temperaturas medias de $8,1^{\circ} \mathrm{C}$ y de $20^{\circ}$ $\mathrm{C}$ en verano. Posee un aire limpio y de calidad, que se percibe al descender desde la cuesta Lo Prado, al abandonar Santiago, y tierras de aptitud agrícola debido a la hidrografía aportada por el estero Puangue. No existe claridad en la fecha de la fundación de Curacaví, pero se cree que se produjo a mediados del siglo XVII, debido a las continuas particiones territoriales efectuadas. Al poseer sus orígenes en la encomienda, Curacaví tuvo vaivenes en la administración civil y en lo eclesiástico, ya que en variadas oportunidades cambiaba de manos, lo que se refleja en la iglesia Nuestra Señora del Carmen, localizada en la plaza.

Su cercanía con Santiago le permitió transformarse en un lugar de paso entre Santiago y Valparaíso-Viña del Mar, lo que ha postergado un mayor desarrollo turístico. Sin embargo, durante la última década se han aprovechado las características de zona tra-

5 Disponible en Internet: http://www.dedaldeoro.cl 
dicional (Figura $\mathrm{N}^{\circ} 4$ ) para desarrollar un turismo rural. Son recorridos guiados de un día, que muestran en la primera mitad los viveros de flores y cactos, lecherías y parcelas agrícolas, para luego, en la segunda mitad, recorrer el ámbito urbano con visitas a la plaza, chicherías, dulcerías, planta de cerveza y museo.

Tras producirse una migración por amenidad a los sectores que presentan parcelas de agrado, también se ha potenciado el turismo por amenidad. Esto mismo le ha llevado a desarrollar una infraestructura turística que actualmente presenta una capacidad de acogida acorde a las visitas que recibe, contando con un hotel que a su vez oficia de resort, con parque y piscinas, moteles, hostales, sitios de camping y un centro turístico con diez cabañas. Todos los años aumenta su demanda turística en el mes de abril, cuando en el estadio de Curacaví se desarrolla la fiesta de la vendimia del licor tradicional chileno: la chicha. En esta fiesta hay también actividades de rodeo y otros juegos tradicionales.

\section{Factores de repulsión del Área Metropolitana de Santiago y Valparaíso-Viña del Mar}

Cualquier migración es resultado de fuerzas de atracción y repulsión. Claro está que los factores de atracción son los servicios de las regiones descritas anteriormente, mientras que los factores de repulsión se originan en los medios naturales y sociales de las regiones de base. Estas son las áreas metropolitanas de Santiago (para el Cajón del Maipo y Curacaví) y de Valparaíso-Viña del Mar para Olmué. La metrópoli de Santiago puede ser considerada prácticamente como la capital latinoamericana más contaminada. Solo la ciudad de Cubatão en Brasil, conocida como el "valle de la muerte", sufre más por la contaminación del aire, suelo y agua. En el caso de Santiago es el smog, especialmente en situaciones de inversión térmica en invierno, el que no puede retirarse de la cuenca de Santiago, situada entre dos cordilleras y montañas secundarias en el norte (cerros Chacabuco, Colorado Chico,

Figura $\mathrm{N}^{\circ} 4$

Reserva La Aurora en Curacaví

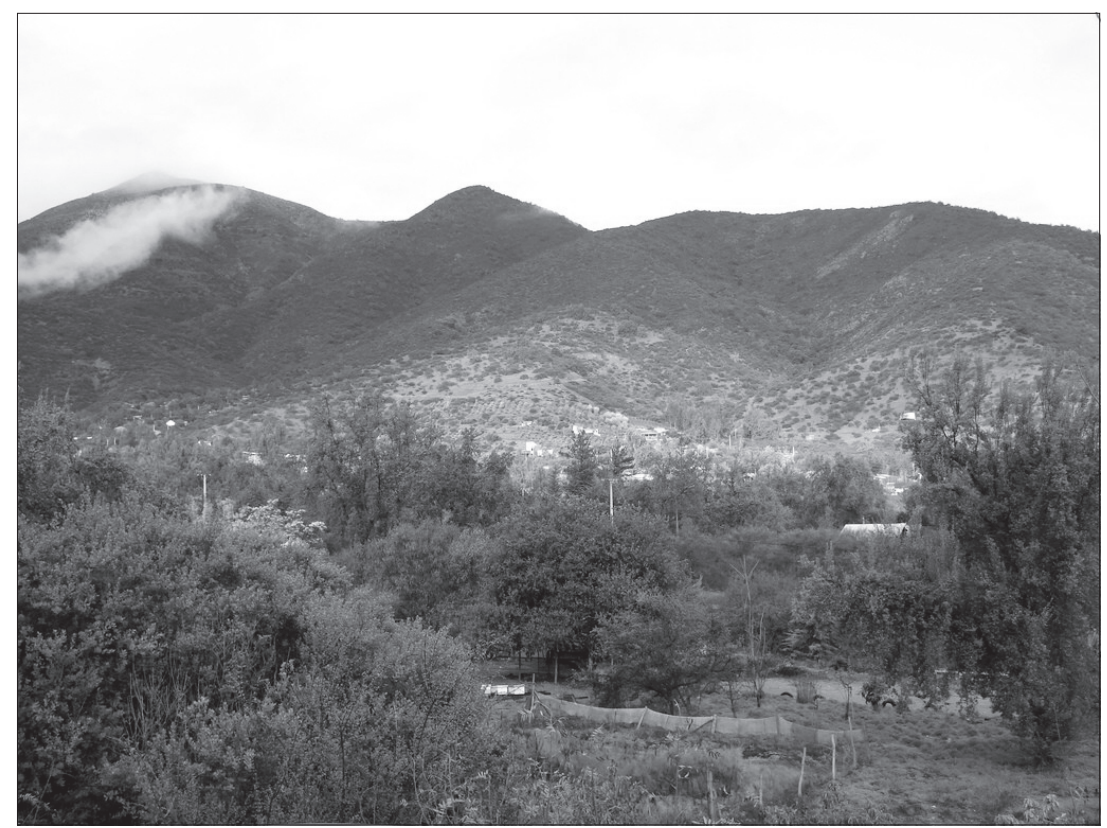

Fuente: Colección personal de los autores. 
$1.577 \mathrm{~m}$, y Blanco, $1.577 \mathrm{~m}$ ) y sur (Angostura, cerros de Peuco de $2.497 \mathrm{~m}$ ). El ruido del tráfico y la densa urbanización pueden ser considerados también como factores de repulsión. En vista de ello, un agente de rechazo corresponde a problemas de salud derivados de la mala calidad del aire en las áreas metropolitanas.

El Área Metropolitana de Valparaíso-Viña del Mar no sufre prácticamente las consecuencias del smog debido a su localización costera, sin embargo, nieblas frecuentes que se forman producto de las frías aguas de la corriente de Humboldt (Perú), reducen la calidad de vida en esta aglomeración de una forma similar. El ruido, el tráfico y largos tiempos de viaje son factores de repulsión que afectan tanto las aglomeraciones costeras como del valle central. Para disminuir los lapsos, corporaciones privadas incluso han comenzado a construir carreteras concesionadas de alta velocidad.

Los factores más importantes de repulsión incluyen los altos niveles de delincuencia, la falta de seguridad y, sobre todo, la estandarizada y densa urbanización. De hecho, en Curacaví, la gran mayoría de los migrantes por amenidad buscaban seguridad y tranquilidad, que consiguieron en las parcelas de $5.000 \mathrm{~m}^{2}$ y más (Plaza, 2008). Cuando la globalización penetró el mercado inmobiliario, casas para familias pequeñas solo eran ofrecidas por inmobiliarias internacionales y con formas arquitectónicas muy estandarizadas. Las casas individuales han sido casi completamente sustituidas por estas casas prefabricadas en comunidades enrejadas. La alternativa es vivir en un departamento de un gran edificio, pero las opciones de individualización son aún más limitadas.

Sin embargo, es necesario mencionar que los precios del suelo y las casas no son factores de repulsión para los ciudadanos de Valparaíso y Santiago, ya que los precios en el Cajón del Maipo, Olmué e incluso en Curacaví son casi iguales que los de la cuarta parte más atractiva de las grandes aglomeraciones.

Las condiciones para la migración por amenidad en el caso chileno pueden ser re- sumidas de la siguiente forma: la inversión es alta y solo alcanzable por los sectores de mayores ingresos; si bien no es necesario, el vehículo facilita las cosas de sobremanera. Como los lotes en las regiones están acondicionados por infraestructura de servicios de urbanización, el agua y la electricidad es provista por las inmobiliarias, pero el tratamiento de las aguas residuales tiene que ser previsto por los dueños, siendo muchas veces un problema de difícil resolución y con un marco legal aún en formación.

\section{El medio ambiente construido por los migrantes por amenidad en Olmué, Cajón del Maipo y Curacaví}

Dos formas distintas de asentamientos por amenidad pueden ser encontradas en estas regiones de emigrantes de Santiago y las aglomeraciones costeras (Figura $N^{\circ} 5$ ): condominios (comunidades enrejadas) y parcelas de agrado (lotes de agrado). Este último puede ser insular u organizado en condiciones de condominios, que son las ya mencionadas agrupaciones de parceleros, sin embargo, el discurso desde la inmobiliaria para el cliente es que se trata de un condominio.

Por otra parte se encuentran los condominios, la forma chilena de comunidades enrejadas, estos son construidos por agencias inmobiliarias, las que desarrollan sus proyectos con un alto grado de flexibilidad y bajo nivel de regulación. Esto permite que sea legal cercar el límite del condominio y poner una muralla para excluirlo del espacio público. En Santiago y Valparaíso-Viña del Mar esos condominios están caracterizados por arquitectura estandarizada; en cambio, en el Cajón del Maipo, Olmué y Curacaví las agencias permiten la construcción de casas según la elección arquitectónica individual, pues solo se les ofrece el terreno y la infraestructura (multicanchas, piscinas y juegos infantiles). Otra diferencia es el tamaño del lote: dentro de la aglomeración, incluso en comunidades enrejadas de alta calidad, no sobrepasará los $300 \mathrm{~m}^{2}$.

La única opción de escapar a esas restricciones es comprar una "parcela de agrado", amparada en el DFL 3.516 de 1980, que 
como se señaló permitió subdividir el suelo rústico en unidades no menores a $5.000 \mathrm{~m}^{2}$, dando paso a la construcción de casas individuales sobre estos lotes. Esta es la razón por la cual grandes áreas de antiguas tierras rurales ahora están urbanizadas (Borsdorf, Hidalgo \& Sánchez, 2007). Existen algunos lotes individuales o insulares, pero en la mayoría de los casos las parcelas de agrado también son desarrolladas y urbanizadas por compañías inmobiliarias. Sin embargo, la construcción de la casa está casi siempre a cargo del propietario. En muchas oportunidades la agencia ofrece la reja y la instalación del sistema de seguridad (portal de entrada y un guardia las 24 horas). Pueden ser consideradas como "condominios de facto" en contraste con los condominios que se acogen a la Ley de Copropiedad 19.537 de 1997 (MINVU, 1997).

Los datos del Instituto Nacional de Estadísticas de Chile permiten una estimación de la situación para el año 2002. Solo admiten tener una imagen rápida de la situación en el Cajón del Maipo, pero no es suficiente para Olmué, ya que el grueso de la migración por amenidad empezó en el año 2002, cuando el paso por la carretera Cuesta la Dormida fue consolidado y un moderno y confortable sistema fue instalado para unir Olmué con Santiago. El tiempo de viaje fue reducido de $4 \mathrm{hrs}$. a $2 \mathrm{hrs}$. o incluso 1,5 hr. El año 2002 marcó el rápido ingreso a las tierras de Olmué y puede ser fácilmente demostrado ya que casi todas las parcelas de agrado fueron urbanizadas a partir de ese entonces. En Curacaví, en el año 2002 es posible apreciar los primeros contingentes de migrantes por amenidad tras realizar análisis demográficos, pero será en 2012 cuando se determine la cantidad absoluta a la fecha de estos migrantes, ya que han proliferado los condominios insertos en parcelas de agrado a partir de 2002, que son el lugar de destino de los migrantes. En la Figura $N^{\circ} 6$ es posible apreciar los flujos migratorios producidos en las tres áreas de estudio. En primer término, cabe destacar que tanto para San José de Maipo y Curacaví los principales contingentes de población provienen de comunas de la Región Metropoli-

Figura $N^{\circ} 5$

Publicidad para lotes de parcelas en Olmué

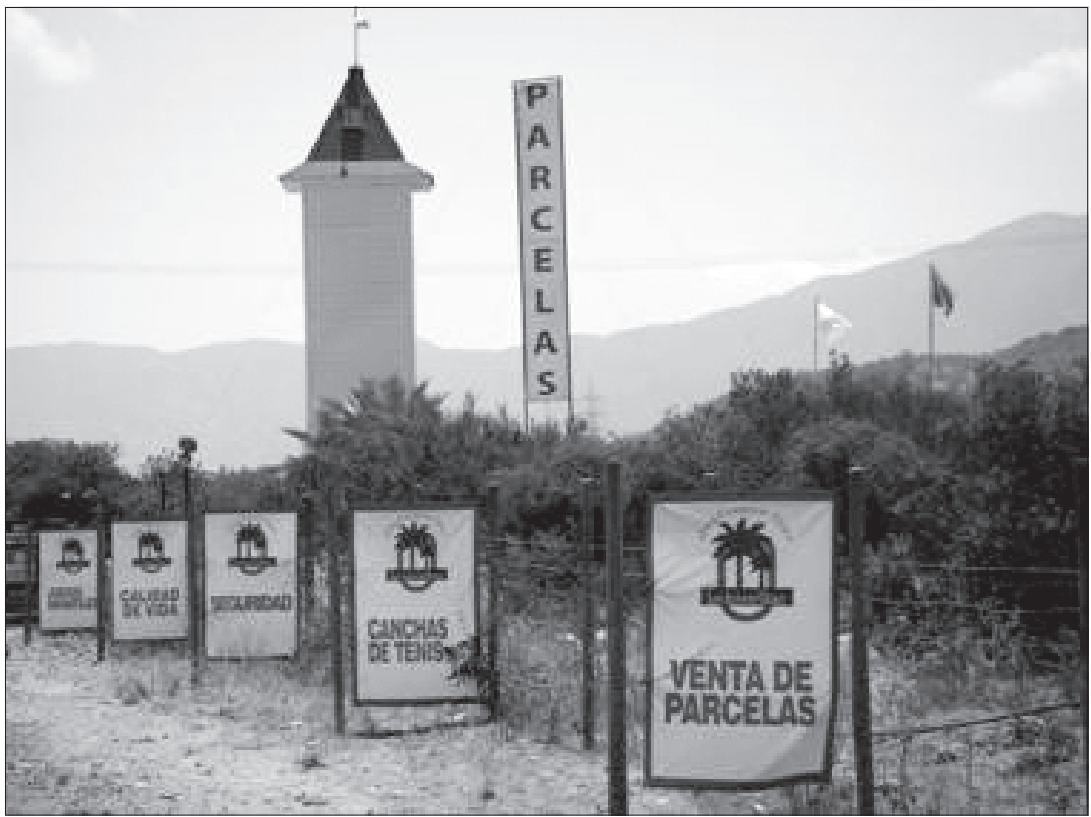

Fuente: Colección personal de los autores. 
tana, en especial aquellas de la periferia como La Florida y Maipú y otros de comunas de barrios altos como Ñuñoa y Las Condes. En Olmué, en tanto, los flujos migratorios tienen procedencia de la Región de Valparaíso, desde comunas como Viña del Mar, Valparaíso, Quilpué y Quillota.

Incluso así, en el período 1997-2002, exactamente 1.253 personas se mudaron a Olmué. La migración diaria por trabajo o educación a Santiago para el año 2002 fue de 64 personas y 346 se desplazaron hacia Valparaíso-Viña del Mar (INE). Junto con los adultos mayores, la población de la migración por amenidad para el año 2002 puede ser estimada en un total de 1.000 personas, un $8 \%$ de toda la población. Hoy el porcentaje puede alcanzar un $20 \%$.

En Olmué hoy día existen once parques con 21 a 50 parcelas de agrado, uno con 18 lotes y dos con 10 u 11 lotes. Sin embargo, en esta región algunas parcelas están localizadas individualmente en las orillas de la carretera (Figura $N^{0} 7$ ).
Como no hubo mayores cambios en la accesibilidad al Cajón del Maipo (salvo por la construcción de la línea de metro a Puente Alto, puerta de entrada al valle que merece ser mencionada), la situación en 2002 permite una buena estimación de las condiciones de hoy. En ese año, 1.804 personas se desplazaron a la Región Metropolitana de Santiago, la mayoría de ellos a las comunidades de trabajo en el centro de la ciudad y los Ilamados barrios altos (1.014 personas). Esto corresponde al $13,5 \%$ de las personas que se desplazan entre la población local. Integrando a las dueñas de casas y los niños, hasta el 30\% de la población puede ser considerada como migrantes por amenidad. La Figura $N^{\circ} 8$ expone la situación actual de parques residenciales y condominios, infraestructura hotelera y el índice de dimensión humana de la comuna.

En el Cajón del Maipo existen cuatro parques de lotes de agrado con entre $63 \mathrm{y}$ 95 lotes, dos con entre 28 y 62 lotes, y tres con entre 8 y 27 lotes (Figura $N^{\circ} 8$ ).

Figura $\mathrm{N}^{\circ} 6$

Flujos de Migración 1992-2002 desde Santiago a Olmué, Cajón del Maipo y Curacaví

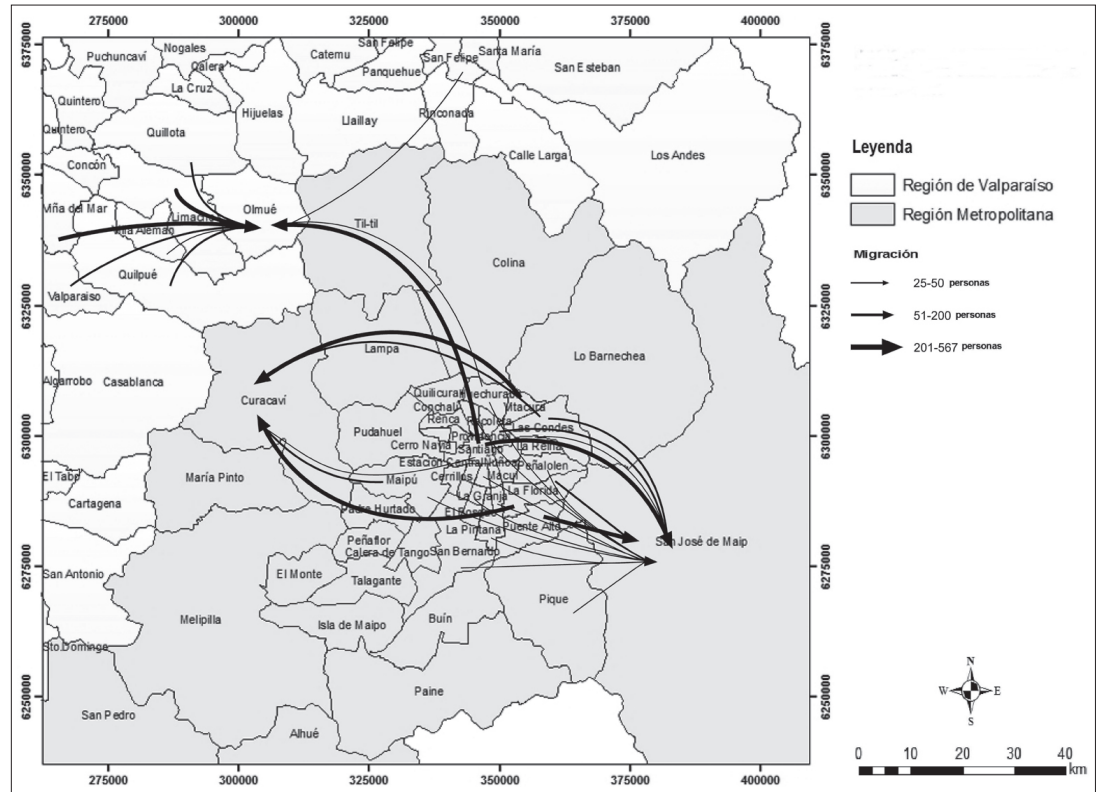

Fuente: Elaboración propia. 
Figura $\mathrm{N}^{\circ} 7$

Hoteles, Índice de Dimensión Humana y parcelas de agrado en Olmué, 2008

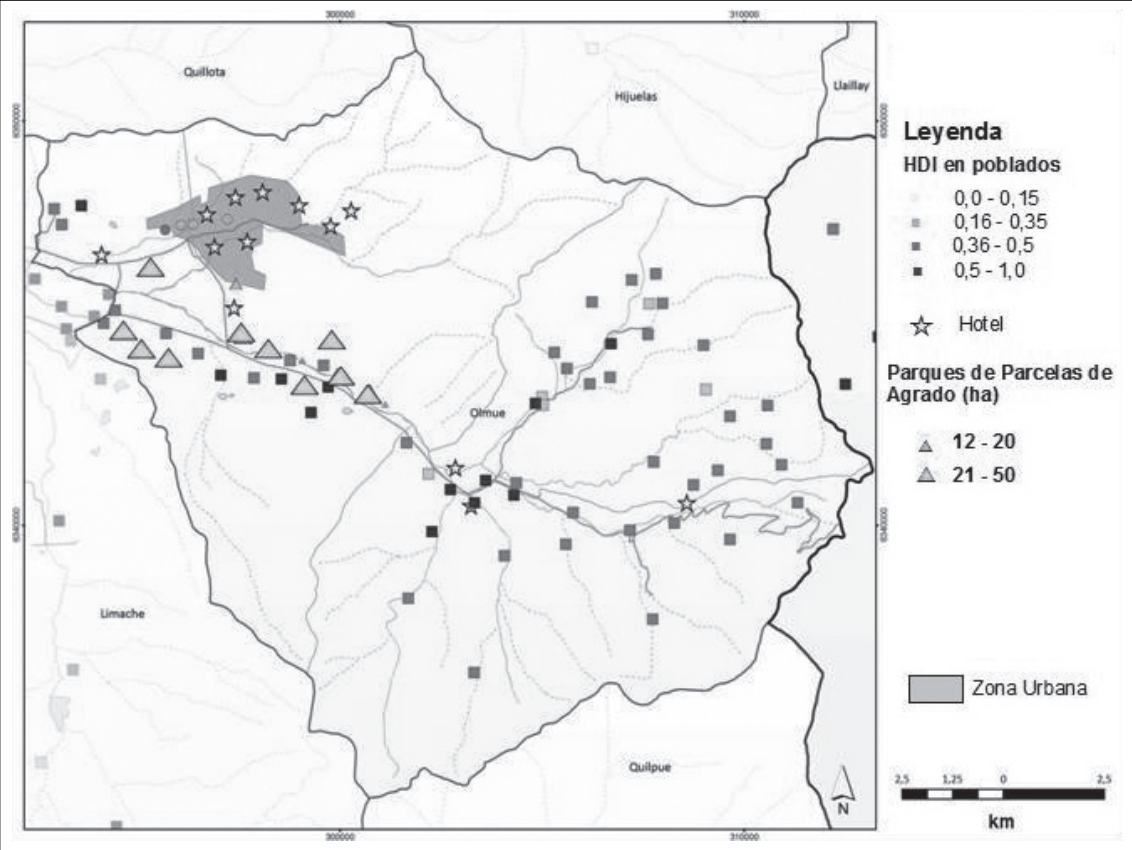

Fuente: Elaboración propia.

Figura $\mathrm{N}^{\circ} 8$

Hoteles, Índice de Dimensión Humana y parcelas de agrado en Cajón del Maipo, 2008

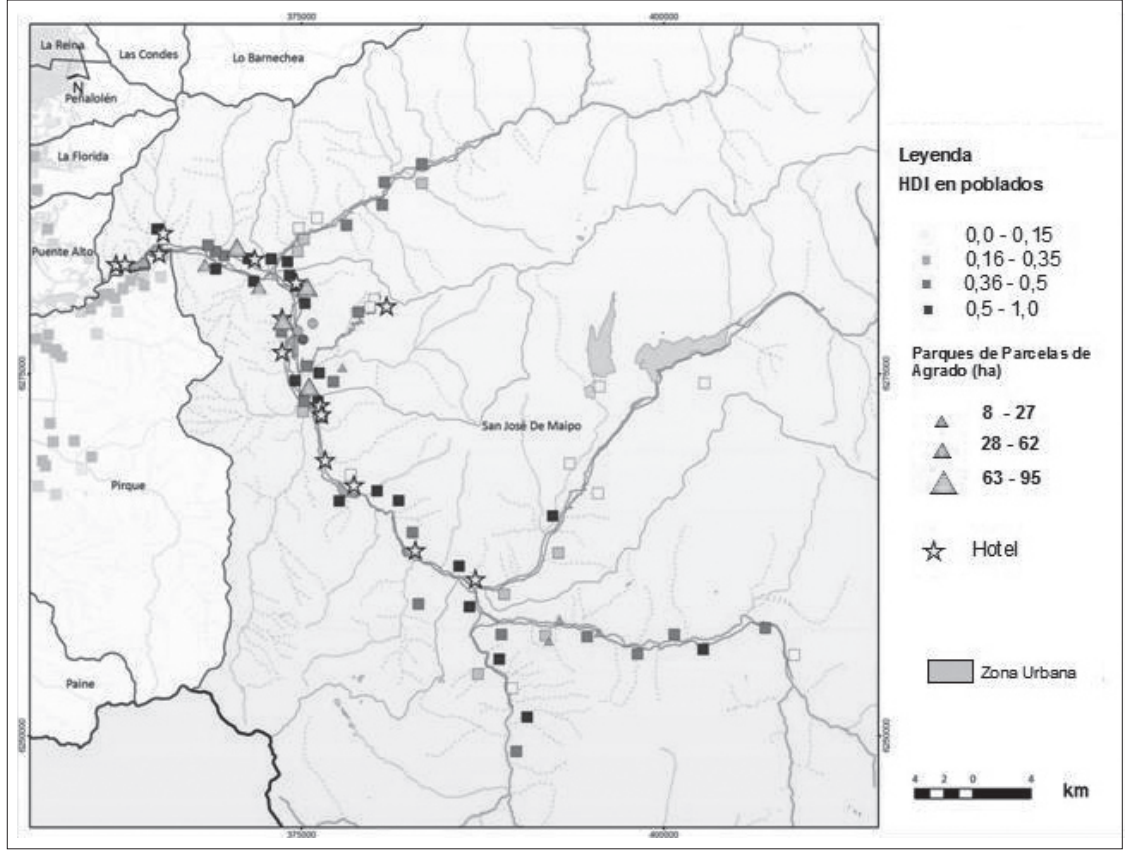

Fuente: Elaboración propia. 
En Curacaví la tranquilidad del valle y de los habitantes, sumado a la ampliación y mejoramiento de la ruta 68 que une Santiago con Valparaíso desde los años 90 por una concesionaria extranjera, ha sido un lugar que ha atraído a gran cantidad de población. En 2002 se registró un crecimiento de 5.245 habitantes, de los cuales 1.273 son resultado del proceso migratorio (Figura $\mathrm{N}^{\circ} 9$ ).

\section{Motivos de migración por amenidades}

De las entrevistas a expertos es posible extraer otro punto de vista acerca del fenómeno de las amenidades. Ya se han mencionado la calidad de vida, el microclima, la ausencia de ruido, la seguridad, vida rural, cortos tiempos de viaje en un nuevo entorno y la vista a las montañas como motivaciones de los migrantes. Como facilitadores se mencionaron los siguientes temas: accesibilidad, comunicación con los respectivos facilitadores de las tecnologías de la información, disponibilidad de tierra, re- ducido arraigo socioespacial y servicios de confort.

El marco de las condiciones pueden ser consideradas como la doctrina neoliberal y el retroceso del Estado y de la comunidad en el ordenamiento y control legal (desregulación), la disposición de los campesinos a vender sus tierras, posiblemente por su concentración sobre nuevos cultivos comerciales, los que obtuvieron buenos precios en el mercado mundial y pudieron ser cultivados en invernaderos en forma de jardinería, lo que necesita menos tierra. Por otro lado, la creciente competencia global por cultivos comerciales llevó a la disminución de la producción de granos. Mientras la globalización conllevó a la estandarización de la arquitectura en las metrópolis, los estilos de vida individuales solo pueden ser vistos y realizados en el campo.

En estos términos es relevante el rol que cumplen los actores clave. El ámbito gubernamental a cargo de los municipios y sus diferentes divisiones está tendiendo hacia una planificación que satisfaga las necesidades

Figura $\mathrm{N}^{\circ} 9$

Hoteles, Índice de Dimensión Humana y parcelas de agrado en Curacaví, 2008

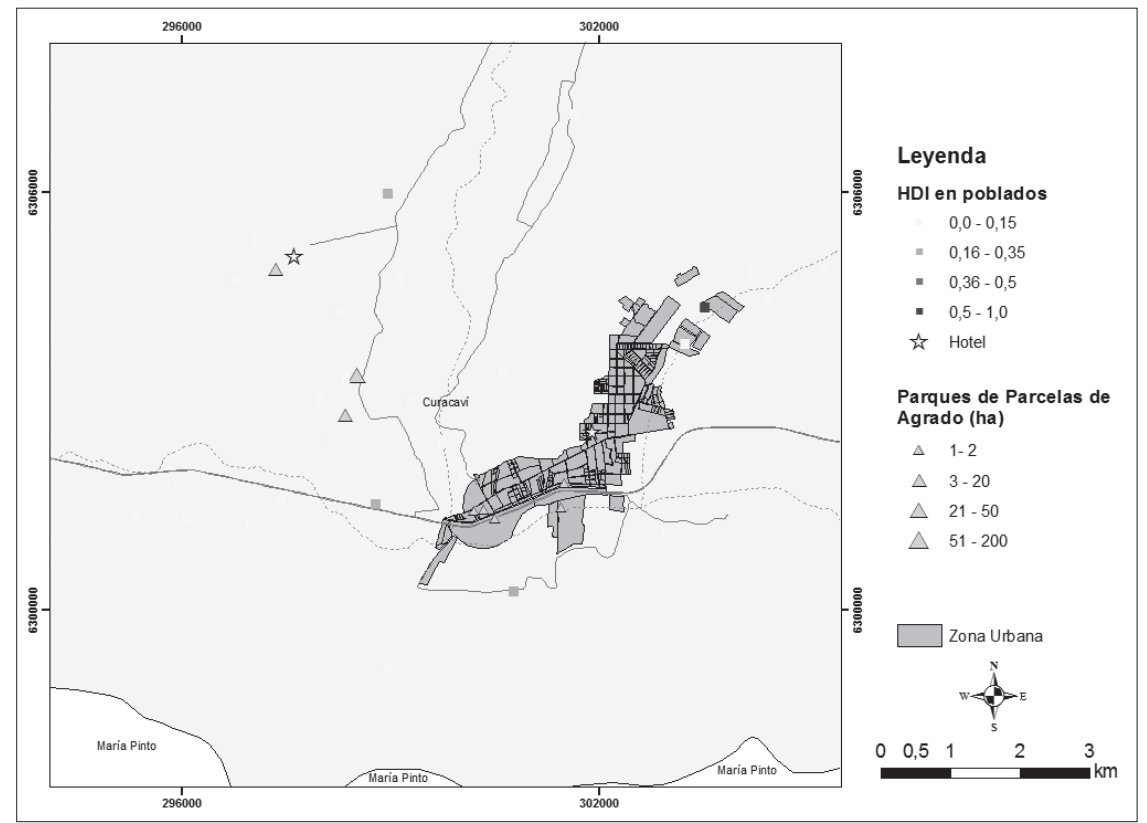

Fuente: Elaboración propia. 
de los habitantes y mejore su calidad de vida, en torno a vivienda, salud, educación y medio ambiente. Sin embargo, los municipios de comunas tradicionalmente rurales consideran que urbanizar es una viable opción de desarrollo, pues genera empleos. Sumado al marco legal que permite la urbanización en parcelas de agrado, las inmobiliarias se valen de dichos permisos además de las condiciones propias del entorno natural de las comunas para generar nuevos proyectos bajo la denominación de condominios. No obstante ello, no contempla el daño que se produce al medio ambiente, como la presión sobre el medio natural y la pérdida de los mejores suelos agrícolas. Inmediatamente se generan nuevas demandas que los municipios deben enfrentar: mayor infraestructura vial, establecimientos sanitarios, establecimientos educacionales y la pérdida de la seguridad. Sin lugar a duda que estos permisos pueden verse contrarios al plan de desarrollo comunal, lo cual no es un problema para los municipios ya que ante esto se valen de la Ley Orgánica Constitucional de Municipalidades, N 18.965, la cual establece como facultades al municipio de modificar el plan de desarrollo comunal.

Otro de los actores clave que hace aún más permisible los cambios que se generan en las comunas es la propia comunidad representada por sus habitantes. Son generalmente incapaces de organizarse y manifestarse ante un problema comunal, transformándose en actores pasivos. Algunas comunas como Curacaví, teniendo conocimiento del comportamiento de los habitantes en general, han impulsado instancias de participación en la cual la comunidad sea parte de la planificación teniendo derecho a opinión, como acontece con los cabildos abiertos.

\section{Consideraciones finales}

En contraste con el abrumador proceso de globalización, que afecta incluso las áreas más remotas del mundo, sus promotores, las organizaciones internacionales, declaran a la sustentabilidad como el instrumento de evaluación para medir cualquier desarrollo regional. Este concepto demanda una evaluación de los impactos ambientales, coherencia social y crecimiento econó- mico de modo que las formas de vida de las generaciones futuras no se vean afectadas. Bajo este aspecto la migración por amenidad chilena tiene un impacto económico muy positivo. Ha creado empleos (industria, inmobiliaria, industria constructora, transporte, distribución de energía, servicios cuidadores de casas y lotes, jardineros y otros), mayor poder de compra en los lugares donde se ha materializado y también ayuda a que exista y se expanda el comercio, además aumenta los impuestos municipales. También contribuye a que regiones remotas sobrevivan al mejorar su imagen para actividades turísticas y atraigan aún más inmigrantes. En el caso argentino, también la migración por amenidad concluye en estrategias que contribuyen al desarrollo sustentable de la cultura y del medio natural, lo que finalmente se traduce en el incremento de nuevos destinos turísticos.

Por otro lado, la planificación urbana y territorial es insuficiente. La incontrolable creación de más y más parques residenciales afecta no solo el funcionamiento de las comunidades locales, sino que aún más a la ecología y el medio ambiente de estas regiones. No está previsto tampoco un ordenamiento del espacio habitado a futuro, ni se promueve la planificación estratégica. El cambio del uso del suelo y el consumo de tierras junto con las desintegradas y poco armoniosas estructuras urbanas deben ser consideradas como una problemática a largo plazo. Escasos son los esfuerzos de las áreas estudiadas por crear viviendas sociales integradas a los desarrollos residenciales de parcelas de agrado, para no perturbar el deseo de exclusividad de los nuevos migrantes, sin embargo, estos inmigrantes están dispuestos a integrarse a las comunidades locales, pero a la larga los conflictos entre locales y los emigrantes pueden emerger, por la diversidad de intereses. Los altos costos de la infraestructura urbana resultan en una urbanización dispersa en vez de condensada.

Se concluye con una evaluación de las oportunidades y riesgos de la migración por amenidad en Chile. Existen numerosas oportunidades: los inmigrantes ayudan a sostener la economía local y, debido a sus demandas turísticas, ayudan a salvaguardar las tradiciones y costumbres locales donde 
muchos de ellos las exaltan. La migración usa la infraestructura turística y es un factor de utilización e incluso expansión; además, mejora la imagen de región turística. Los inmigrantes contribuyen al ingreso municipal y pueden ayudar a instalar un sistema de gobierno apropiado debido a su alto nivel educacional que conforma una masa crítica más participativa. Así es como se llega a la paradoja que la migración por amenidad por sí misma es un producto de la globalización y la creciente riqueza, pero ayuda a confrontar la globalización iniciando factores sustentables para la economía y la cultura local. Estas son importantes oportunidades para los lugares de destino y las generaciones futuras.

Sin embargo, existen ciertos riesgos. La pérdida de valiosa tierra agrícola, el consumo de agua en un medio semidesértico, el costo de infraestructura permanente, que es usada en parte durante solo algunas temporadas, el mayor consumo de energía, el cambio en el uso del suelo y la disminución de la superficie agrícola son efectos negativos que especialmente conciernen y afectan al ecosistema. No obstante estos riesgos, no pueden ser solo vistos como peligros, pueden ser considerados también como oportunidades. Si los posibles riesgos son reconocidos a tiempo se pueden desarrollar estrategias para prevenirlos. Solo queda la esperanza que esto se llevará a cabo en Chile y en las áreas de estudio lo antes posible.

En este sentido, la constatación de las "nuevas y renovadas" formas en que se construye la ciudad contemporánea y los sustratos que esta necesita para su desarroIlo, indican la necesidad de pensar de otro modo la planificación y ordenamiento de su expansión. La comentada reforma que se Ileva a cabo a la LGUC es una instancia que debe ser aprovechada para regular la urbanización dispersa y así contribuir a mitigar las externalidades de la formación de nuevos asentamientos, muchas de las cuales no solo se pueden alcanzar con mayores inversiones, sino que con el diseño de estrategias de ordenamiento territorial que incorporen las dimensiones sociales y espaciales como ejes conductores y no como "datos de la causa".
Finalmente, cabe señalar lo importante que es el DFL 3.501, que posibilita la urbanización desmedida en territorios en los cuales no tienen repercusión los instrumentos de planificación territorial como el Plano Regulador Metropolitano de Santiago (PRMS) de 1994, especialmente en aquellos que presentan características rurales, ubicados en las periferias de las áreas metropolitanas y que al largo plazo acabarán con el suelo de mejor aptitud agrícola.

Se requiere de medidas urgentes para preservar el medio y también las amenidades, fundamentalmente del medio natural, presentes tanto en las comunas de estudio como en otras que poseen características similares. Las medidas deben estar referidas a la planificación ordenada y participativa en la cual tengan opinión todos los actores clave, que rompa con los excesivos conflictos de intereses de órganos sectoriales existentes. Ante ello, la planificación estratégica está Ilamada a ser una buena herramienta que logre la conciliación de los múltiples intereses, para aplicarse a los instrumentos de planificación y regulatorios y también a los lineamientos a los que apunta el desarroIlo comunal.

\section{Referencias bibliográficas}

Boletín 2691-01. Mensaje presidencial DFL 3.516. Santiago: República de Chile, $\mathrm{s} / \mathrm{f}$

BORDE, J. y GÓNGORA, M. Evolución de la propiedad rural en el valle del Puangue. Santiago: Editorial Universitaria, 1956.

BORSDORF, A. \& HIDALGO, R. New dimensions of social exclusion in Latinamerica: from gated communities to gated cities. The example of Santiago de Chile. Land Use Policy, 2008a, No 25, p. 153-160.

BORSDORF, A. \& HIDALGO, R. Der urban sprawl in Europa und Lateinamerika: ein vergleich der entwicklungen europäischer und lateinamerikanischer agglomerationen. Mitteilungen der österreichischen geographischen gesellschaft. (upcoming), 2008b. 
BORSDORF, A.; HIDALGO, R. \& SÁNCHEZ, R. A new model of urban development in Latin America: The gated communities and fenced cities in Santiago de Chile and Valparaíso. Cities. The International Journal of Urban Policy and Planning 24, 2007, № 5, p. 365-378.

COMISIÓN NACIONAL DE MEDIO AMBIENTE (CONAMA). Identificación de instrumentos y normativas de ordenamiento territorial ambiental y definición de situaciones críticas. Santiago: CONAMA, 1999.

CHAVERRI, P. Cultural and enviromental amenities in peri-urban change: the case of Sant Antonio de Escazú, Costa Rica. In: MOSS, L. (ed.). The Amenity Migrants. Seeking ans Sustaining Mountains and their Cultures. Wallingford: CABI, 2006, p. $187-$ 199.

ELÓRTEGUI, S. \& MOREIRA, A. Parque Nacional La Campana. Origen de una reserva de la biosfera en Chile central. Santiago: Taller La Era, 2007.

ESCOLANO, S. \& ORTIZ, J. Las migraciones intrametropolitanas como factor de diferenciación socioespacial. En: Santiago, Taller nacional sobre migración interna y desarrollo en Chile: diagnóstico, perspectivas y políticas, CELADE - CEPAL, 2007.

HIDAlGO, R. Post-suburbia o posturbia? Les mégaprojets résidentiels dans la périphérie de Santiago du Chili. Revue Géographique de l'Est, No 3-4, 2005, p. 209-218.

HIDALGO, R.; SALAZAR, A.; LAZCANO, R.; ROA, F.; ÁLVAREZ, L. y CALDERÓN, M. Transformaciones socioterritoriales asociadas a proyectos residenciales de condominios en comunas de la periferia del área metropolitana de Santiago. Revista INVI, 2005, No 54, p. 104-133.

INSTITUTO NACIONAL DE ESTADÍSTICAS (INE). Glosario censo 2002. Santiago: INE, 2002.

JANOSCHKA, M. Wohlstand hinter Mauern
Private Urbanisierungen in Buenos Aires. Wien: ÖAW, ISR Forschungsberichte 28, 2002.

JANOSCHKA, M. \& BORSDORF, A. Condominios fechados and barrios privados: the rise of private residential neighbourhoods in Latin America. In: GLASZE, G.; WEBSTER, C. \& FRANTZ, K. (eds.). Private cities: global and local perspectives. Studies in Human Geography. London (forthcoming), 2005.

KUENTZEL, W. \& MUKUNDAN, V. Tourism and amenity migration, a longitudinal analysis. Annals of Tourism Research, 2005, № 2, p. 419-438.

MATURANA, A. Transformaciones en la configuración territorial del espacio rural en Chile: la subdivisión de predios rústicos en la comuna de Puerto Varas, X Región: a través del Decreto Ley No 3.516 de 1980. Tesis Magíster en Asentamientos Humanos y Medio Ambiente. Santiago: Instituto de Estudios Urbanos y Territoriales, Pontificia Universidad Católica de Chile, Chile, 2002.

MINISTERIO DE AGRICULTURA (MINAGRI). Decreto Ley 3.516, establece subdivisión de predios rústicos. Santiago: MINAGRI, 1980.

MINISTERIO DE VIVIENDA Y URBANISMO (MINVU). Ley 19.537 de copropiedad inmobiliaria. Santiago: MINVU, 1997.

MOSS, L. (ed.) The amenity migrants. Seeking and sustaining mountains and their cultures. Wallingford: CABI, 2006.

OTERO, A. et al. Amenità migration in the Patagonian mountain community of San Martín de los Andes, Neuquén, Argentina. In: MOSS, L. (ed.): The amenity migrants. Seeking and sustaining mountains and their cultures. Wallingford: CABI, 2006, p. 200-211.

PERLIK, M. Stadt-und industrieentwicklung in europäischen gebirgsräumen. In: BORSDORF, A. \& GRABHERR, G. (eds.). Internationale Gebirgsforschung. Wien: Innsbruck, 2006, p. 115-128. 
PLAZA, F. Migraciones por amenidades en comunas periféricas a las áreas metropolitanas de Santiago y Valparaíso. Casos de estudio: Curacaví y Casablanca. Seminario de grado Licenciatura en Geografía. Santiago: Instituto de Geografía, Facultad de Historia, Geografía y Ciencia Política, Pontificia Universidad Católica de Chile, Chile, 2008.

SABATINI, F. Transformación urbana y dialéctica entre integración y exclusión. Reflexiones sobre las ciudades latinoamericanas y notas sobre Santiago de Chile. Santiago: Instituto de Estudios Urbanos y Territoriales, PUC, 1998.
STEWART, S. Amenity migration. LUFT \& MACDONALD, S. (eds.) Trends 2000: shaping the future. Lansing: $5^{\text {th }}$ Outdoor Recreation \& Tourism Trends Symposium. Department of Park, Recreation and Tourism Resources, Michigan State University, 2002, p. 369-378.

WILHELMY, H. \& A. BORSDORF 1984: Die Städte Südamerikas. Vol. 1. Stuttgart, Berlin.

YIN, L. \& MULLER, B. Residential location and the biophysical environment: exurban development aggents in a heterogeneous landscape. Environment and Plannning B: Planning and Dessign, 2007, vol. 34, p. 279-295. 